Check for updates

Cite this: RSC Adv., 2020, 10, 24159

\title{
Rubia tinctorum root extracts: chemical profile and management of type II diabetes mellitus
}

\author{
Enas E. Eltamany, (D) a Mohamed S. Nafie, (D) ${ }^{\mathrm{b}}$ Dina M. Khodeer, ${ }^{c}$ Aya H. H. El-Tanahy, ${ }^{d}$ \\ Maged S. Abdel-Kader, ${ }^{*}$ Jihan M. Badr (D) and Reda F. A. Abdelhameed (D) ${ }^{a}$ \\ The chemical and biological profiling of the root extracts of Rubia tinctorum was performed. The activities \\ of different extracts were determined considering the antidiabetic effect against type II diabetes mellitus \\ together with anti-obesity and hepatoprotective effects and lipid profile. The methanolic extract of Rubia \\ tinctorum exhibited significant results in decreasing body weight, improving lipid profile, normalizing \\ hyperglycaemia, insulin resistance, hyperinsulinemia. Additionally, it showed enhancement of liver tissue \\ structure and function. The methanolic extract, being the most significant one, was subjected to LC- \\ HRMS analysis to determine its chemical constituents. Finally, the chemical constituents were evaluated \\ by molecular docking study that was carried out to identify the interaction of a panel of 45 compounds \\ in silico and to correlate the structures to their anti-diabetic activity. Among the tested compounds, 1- \\ hydroxy-2-hydroxymethyl anthra-quinone and naringenin-7-O-glucoside showed the most potent \\ activity as $\alpha$-amylase inhibitors.
}

Received 20th April 2020

Accepted 16th June 2020

DOI: $10.1039 / \mathrm{dOra03442h}$

rsc.li/rsc-advances

including anti-bacteria, antithrombic, anticancer, anti-

\section{Introduction}

Diabetes mellitus and obesity are important health problems worldwide. They contribute to the development of various pathological processes such as hypertension, cardiovascular diseases, hyperlipidaemia, certain types of cancer and even Alzheimer's. ${ }^{1,2}$ There is a strong correlation between diabetes and obesity, where adipose tissue has an important role in diabetes, a disease characterized by hyperglycemia, insulin hyposecretion, and insulin resistance. ${ }^{3,4}$ The exploitation of phyto-medicine as a therapy for diabetes as well as obesity is a crucial issue for the development of safer alternatives to pharmaceuticals which not only decrease blood glucose but also enhance the antioxidant system. ${ }^{5}$ The genus Rubia belongs to the family Rubiaceae and comprises about 70 species. ${ }^{6}$ Previous research on Rubia species yielded the isolation and chemical identification of about 250 compounds with different chemical classes which possess diverse pharmacological activities

${ }^{a}$ Department of Pharmacognosy, Faculty of Pharmacy, Suez Canal University, Ismailia 41522, Egypt

${ }^{b}$ Department of Chemistry, Faculty of Science, Suez Canal University, Ismailia 41522, Egypt

'Department of Pharmacology \& Toxicology, Faculty of Pharmacy, Suez Canal University, Ismailia 41522, Egypt

${ }^{a}$ Damietta Health Affairs Directorate, Damietta, Egypt

${ }^{e}$ Department of Pharmacognosy, College of Pharmacy, Prince Sattam Bin Abdulaziz University, 173, AlKharj 11942, Saudi Arabia. E-mail: mpharm101@hotmail.com; Tel: +966545539145

${ }^{f}$ Department of Pharmacognosy, Faculty of Pharmacy, Alexandria University, Alexandria 21215, Egypt inflammatory and anti-oxidant. ${ }^{7-10}$

Rubia tinctorum L. (Madder root) was used as a source of red dyes in ancient Egypt. ${ }^{11}$ In addition, several ethnobotanical surveys have reported its use for treatment of various ailments, such as cardiovascular disease, ${ }^{12,13}$ liver pain, diarrhea, ${ }^{14,15}$ rheumatism ${ }^{16}$ and kidney stones. ${ }^{17,18}$ Moreover numerous biological studies have been extensively conducted on $R$. tinctorum and proved its therapeutic potential as antiplatelet aggregation, ${ }^{19}$ antitumor, ${ }^{20}$ hepatoprotective, ${ }^{21}$ vasoconstriction and protective effect on aorta. ${ }^{22}$ The current work was designed to evaluate the antiobesity, antidiabetic and hepatoprotective efficacy of different extracts of $R$. tinctorum along with profiling of potent bioactive components responsible for the antidiabetic activity. In our strategy, we used LC-HRMS technique to identify the phytochemicals in the root extract of $R$. tinctorum then to determine the binding mode of the tested compounds with $1 \mathrm{HX} 0$ as $\alpha$-amylase inhibitor by using molecular docking tool.

\section{Materials and methods}

2.1. In vitro determination of hypoglycemic activity, liver enzymes and lipid profile

2.1.1. Plant material. The roots of Rubia tinctorum were obtained from the Egyptian market and the identity was confirmed in the Faculty of Science, Suez Canal University. A specimen was deposited at Pharmacognosy Department, Faculty of Pharmacy, Suez Canal University, with a code number 2019-RT. Two kilograms of the roots were dried, powdered and extracted with methanol. The extract was dried under vacuum using rotary 
evaporator to give $250 \mathrm{~g}$ of brownish-red methanolic extract (RM). A weight of $160 \mathrm{~g}$ of the methanol extract were withdrawn and suspended in $200 \mathrm{~mL}$ of distilled water then fractionated with $3 \mathrm{~L}$ of each of hexane, chloroform and ethyl acetate successively. Each of the three extracts was dried under vacuum using rotary evaporator to yield 30, 60 and $40 \mathrm{~g}$ of hexane (RH), chloroform (RC) and ethyl acetate (RE) extracts respectively.

2.1.2. Experimental animals. Thirty-five male Wistar rats were used in the current study. The base line body weight was in the range of 118-152 $\mathrm{g}$. They were kept in clean cages with temperature equals $21 \pm 6{ }^{\circ} \mathrm{C}$ and normal light-dark cycle. They had free permission to water and regular diet or HFD. Study protocol was approved by the Committee of Research Ethics at Faculty of Pharmacy in Suez Canal University (license number 202004R2).

2.1.3. Experimental design. Wistar male rats were distributed into seven groups; with 5 rats in every group. First group of rats was assigned as the normal group and received normal chow diet during the experimentation period. Diabetes mellitus type II was induced in the other six groups by modified high fat diet model. ${ }^{23-25}$ The other five groups were fed with HFD (87.7\% standard diet, $10 \%$ lard fat, $30 \%$ glucose) for 7 weeks followed by small dose of streptozotocin (STZ $1 \% \mathrm{~g} \mathrm{~L}^{-1}$ acetic acid; $30 \mathrm{mg}$ $\mathrm{kg}^{-1}$, S. C). After further five days, blood glucose levels are determined to insure the incidence of diabetes mellitus. After that, rats in Group II (diabetic control group) were given distilled water ( $1 \mathrm{~mL}$ per $\mathrm{kg}$ per day, p. o.) till the end of experiment. Rats in group III were given pioglitazone $(10 \mathrm{mg}$ per $\mathrm{kg}$ per day, p. o.) while rats in group IV, V, VI and VII were given the following extracts RM (200 mg kg $\left.{ }^{-1}\right), \mathrm{RH}\left(200 \mathrm{mg} \mathrm{kg}^{-1}\right), \mathrm{RC}$ (200 $\mathrm{mg} \mathrm{kg}{ }^{-1}$ ) and RE (200 mg kg-1), respectively for further four weeks. After completion of the treatment regimens, final body weight was recorded. The change in body weight was calculated from the following equation: $\Delta$ body weight $=$ (the final body weight - the initial body weight)/initial body weight $\times 100$. Similarly, obesity index was calculated by: obesity index $=$ weight of total adipose tissue/final body weight $\times 100$.

2.1.4. Fasting blood glucose determination. Rats were subjected to overnight fasting. Blood specimens were gathered from each rat's tail tip, and fasting glucose was recorded by the use of an automated blood glucometer (Super Glucocard, Japan).

2.1.5. Liver processing. The rats were sacrificed under anaesthesia. Each rat's liver was quickly dissected and washed out of blood with cold saline solution. The weight of livers was measured and the following formula was used for determining the liver index: (liver weight/body weight $\times 100$ ).

Portion of liver tissue was removed from the biggest hepatic lobe, fixed in formaldehyde and finally stained with hematoxylin and eosin (H\&E).

2.1.6. Measurement of serum biochemical parameters

2.1.6.1. Liver enzymes. Spectrophotometrically method was done with marketable kits (Biocon Diagnostic, Germany) to evaluate serum activity of liver enzymes; alanine transaminase enzyme (ALT) (EC 2.6.1.2), aspartate transaminase enzyme (AST) (EC 2.6.1) in accordance with the protocol reported by the manufacturer. ${ }^{26}$

2.1.6.2. Lipid profile. A spectrophotometric assay kits (Spinreact, Spain) were used to measure serum total cholesterol
(TC)(CHOD-POD), triglycerides (TGs)(GPO-POD, Líquido), highdensity lipoprotein (HDL) (HDLc-P) and low-density lipoprotein (LDL)(LDLc-D) according to the manufacturer's protocol. ${ }^{27,28}$

2.1.6.3. Insulin \& leptin ELISA kits. The level of serum insulin and leptin were determined by a rat insulin and leptin ELISA kits (PELOBIOTECH GmbH-Am Klopferspitz 19-82152 planning-Germany) following the manufacturer's protocol. Insulin resistance was determined using the homeostasis model assessment index for insulin resistance (HOMA-IR) index. ${ }^{29}$

2.1.7. Statistical analysis for the data. Results obtained from the current study were expressed as mean \pm S. E. $M$ and analysed with the version 16 of SPSS program. A one-way analysis of variance (ANOVA) was used to analyse quantitative variables, followed by the multiple comparison test of Bonferroni. Significant variations were measured at $p \leq 0.05$.

\subsection{Preparation of the sample and LC-HRMS analysis}

The mobile phase working solution (MP-WS) was prepared from DI-water : methanol : acetonitrile (50:25:25). One $\mathrm{mL}$ of MPWS was added to $50 \mathrm{mg}$ weighted dry methanolic extract, vortex for $2 \mathrm{~min}$. This step was followed by ultra-sonication for $10 \mathrm{~min}$ then centrifugation for $10 \mathrm{~min}$ at $10000 \mathrm{rpm} .20 \mu \mathrm{L}$ stock $(50 / 1000 \mu \mathrm{L})$ was diluted with $1000 \mu \mathrm{L}$ reconstitution solvent. Finally, the injected concentration was $1 \mu \mathrm{g} \mu \mathrm{L}^{-1}$ where $10 \mu \mathrm{Ls}$ were injected on positive mode. Also, $10 \mu \mathrm{L}$ MP-WS were injected as a blank sample. The used mobile phase consisted of (A): $5 \mathrm{mM}$ ammonium formate buffer $\mathrm{pH} 3$ containing 1\% methanol and (B): $100 \%$ acetonitrile. The flow rate was 0.3 $\mathrm{mL} \min ^{-1}$. The used pre-column was in-line filter disks (Phenomenex, $0.5 \mu \mathrm{m} \times 3.0 \mathrm{~mm}$ ) and the column was $\mathrm{X}$ select HSS T3 (Waters, $2.5 \mu \mathrm{m}, 2.1 \times 150 \mathrm{~mm}$ ). Data processing was via MSDIAL3.52. Master view was used for feature (peaks) extraction from total ion chromatogram based on the following criteria: features should have signal-to-noise greater than 5 (nontargeted analysis) and features intensities of the sample-toblank should be greater than 5 .

\subsection{Molecular docking}

Molecular modelling study was carried out to study the interaction of a panel of 28 anthraquinone and 17 flavonoids in silico and to correlate the structures to their anti-diabetic activity. Molecular docking study was conducted on a computational software basis using the Molecular Operating Environment (MOE 2014.09 Chemical Computing Group, Canada). The threedimensional structures of 1HX0 completed with AC1 as alphaamylase inhibitor was freely accessible from the protein data bank (https://www.rcsb.org/structure/1HX0). ${ }^{30}$ Compounds were chemically optimized and energetically minimized, while the receptor was prepared and manipulated using routine protocol according to Nafie et al. ${ }^{31}$ The active sites were defined using grid boxes of appropriate sizes around the co-crystallized ligands. These compounds were docked into the receptor active site, each ligand-receptor complex was tested for binding energy using MOE and interaction analysis using Chimera as a visualizing software. 
Table 1 Effect of different $R$. tinctorum extracts and pioglitazone $\left(10 \mathrm{mg} \mathrm{kg}^{-1}\right)$ on percent change in body weight and obesity index in the experimental groups of type II diabetic rats ${ }^{a}$

\begin{tabular}{|c|c|c|c|c|}
\hline Group & $\begin{array}{l}\text { Base line body } \\
\text { weight }(\mathrm{g})\end{array}$ & Final body weight $(\mathrm{g})$ & $\%$ change in body weight & Obesity index \\
\hline Normal & $147.5 \pm 2.5$ & $210 \pm 10$ & $42.5 \pm 9$ & $0.83 \pm 0.07$ \\
\hline Diabetic + pioglitazone $\left(10 \mathrm{mg} \mathrm{kg}^{-1}\right)$ & $143.5 \pm 1.5$ & $227.5 \pm 17.6^{\mathrm{b}}$ & $58 \pm 13.6^{\mathrm{b}}$ & $2 \pm 0.36^{\mathrm{b}}$ \\
\hline Diabetic + RM $\left(200 \mathrm{mg} \mathrm{kg}^{-1}\right)$ & $167.5 \pm 7.5$ & $308 \pm 8^{\mathrm{a}, \mathrm{b}, \mathrm{c}}$ & $84 \pm 3.4^{\mathrm{a}, \mathrm{b}}$ & $2.5 \pm 0.89^{\mathrm{a}, \mathrm{b}}$ \\
\hline Diabetic + RH (200 mg kg-1) & $140 \pm 2$ & $333.5 \pm 16.6^{\mathrm{a}, \mathrm{c}, \mathrm{e}}$ & $138 \pm 8.2^{\mathrm{a}, \mathrm{c}, \mathrm{d}}$ & $5.1 \pm 0.17^{\mathrm{a}, \mathrm{c}, \mathrm{d}}$ \\
\hline
\end{tabular}

${ }^{a}$ Results are expressed as mean \pm S. E. M. and analysed using one-way ANOVA followed by Bonferroni's test for multiple comparisons. ${ }^{a} P \leq 0.05$ versus normal group. ${ }^{\mathrm{b}} P \leq 0.05$ versus diabetic group. ${ }^{\mathrm{c}} P \leq 0.05$ versus diabetic + pioglitazone $\left(10 \mathrm{mg} \mathrm{kg}{ }^{-1}\right)$ group. ${ }^{\mathrm{d}} P \leq 0.05 \mathrm{diabetic}+\mathrm{RM}(200 \mathrm{mg}$ $\left.\mathrm{kg}^{-1}\right)$ group, ${ }^{\mathrm{e}} \mathrm{P} \leq 0.05$ diabetic $+\mathrm{RH}\left(200 \mathrm{mg} \mathrm{kg}^{-1}\right)$ group. $n=5$.

Table 2 Effect of different $R$. tinctorum extracts and pioglitazone $\left(10 \mathrm{mg} \mathrm{kg}^{-1}\right)$ on blood glucose level ( $\left.\mathrm{mM} \mathrm{L}^{-1}\right)$, serum insulin (ng L $\mathrm{L}^{-1}$ ), homeostatic model assessment of insulin resistance (HOMA-IR) and serum leptin level $\left(\mathrm{ng} \mathrm{L}^{-1}\right)$ in the experimental groups of type II diabetic rats ${ }^{a}$

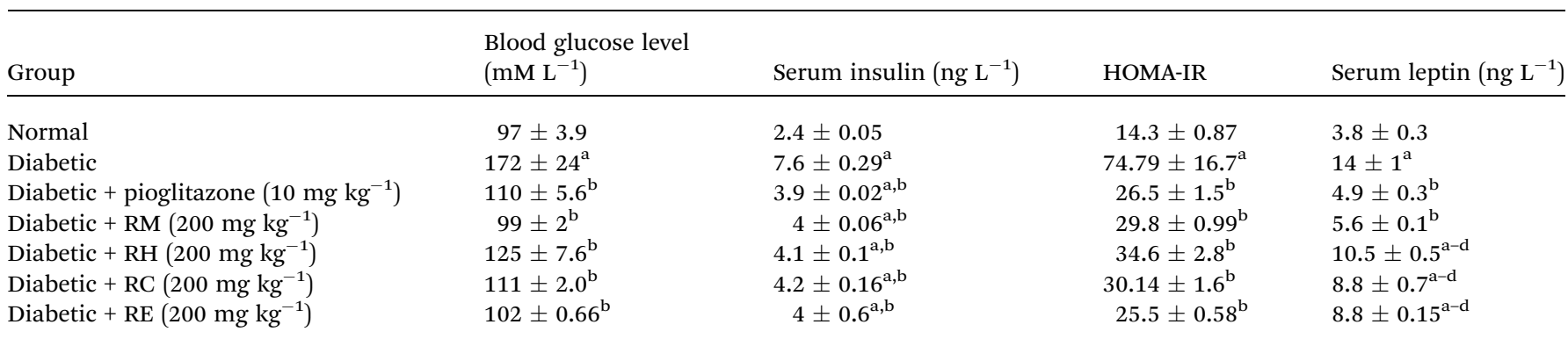

${ }^{a}$ Results are expressed as mean \pm S. E. M. and analysed using one-way ANOVA followed by Bonferroni's test for multiple comparisons. ${ }^{\text {a } P} \leq 0.05$ versus normal group. ${ }^{\mathrm{b}} P \leq 0.05$ versus diabetic group. ${ }^{\mathrm{c}} P \leq 0.05$ versus diabetic + pioglitazone $\left(10 \mathrm{mg} \mathrm{kg}^{-1}\right)$ group. ${ }^{\mathrm{d}} P \leq 0.05$ diabetic $+\mathrm{RM}(200 \mathrm{mg}$ $\mathrm{kg}^{-1}$ ) group. $n=5$.

\section{Results and discussion}

\subsection{Effect of different $R$. tinctorum extracts and pioglitazone (10 $\mathrm{g} \mathrm{kg}^{-1}$ ) on percent change in body weight and obesity index on type II diabetic rats}

Treatment with high fat diet followed with STZ $\left(30 \mathrm{mg} \mathrm{kg}^{-1}\right)$ in diabetic group resulted in a significant increase in final body weight ( $352 \pm 7.5)$, \% change in body weight $(152 \pm 14.1)$ and obesity index $(5.9 \pm 0.5)$ versus normal group $(210 \pm 10)(42.5 \pm$ $9)$ and $(0.83 \pm 0.07)$ respectively at $p \leq 0.05$ (Table 1$)$. Treatment with pioglitazone $\left(10 \mathrm{mg} \mathrm{kg}^{-1}\right)$ for four weeks after induction of diabetes induced significantly decrease in final body weight, \% change in body weight and obesity index when compared with diabetic group at $p \leq 0.05$. Pioglitazone is one member from thiazolidines, as it is PAPR-gamma agonist in particular is known to favorably influence the majority of the components of

Table 3 Effect of different $R$. tinctorum extracts and pioglitazone $\left(10 \mathrm{mg} \mathrm{kg}^{-1}\right)$ on liver index, serum liver enzymes level alanine transaminase (ALT) and aspartate transaminase (AST) in the experimental groups of type II diabetic rats ${ }^{a}$

\begin{tabular}{|c|c|c|c|}
\hline Group & Liver index & $\operatorname{AST}\left(\mathrm{U} \mathrm{L}^{-1}\right)$ & $\operatorname{ALT}\left(\mathrm{U} \mathrm{L}^{-1}\right)$ \\
\hline Normal & $2.3 \pm 0.1$ & $39 \pm 1$ & $34.5 \pm 1.5$ \\
\hline Diabetic & $3.5 \pm 0.2^{\mathrm{a}}$ & $92.5 \pm 0.5^{\mathrm{a}}$ & $78 \pm 2.02^{\mathrm{a}}$ \\
\hline Diabetic + RM $\left(200 \mathrm{mg} \mathrm{kg}^{-1}\right)$ & $2.5 \pm 0.02^{\mathrm{b}}$ & $35 \pm 1.01^{\mathrm{b}, \mathrm{c}}$ & $30 \pm 1.01^{\mathrm{b}}$ \\
\hline Diabetic + RH $\left(200 \mathrm{mg} \mathrm{kg}^{-1}\right)$ & $3.9 \pm 0.07^{\mathrm{a}, \mathrm{c}, \mathrm{d}}$ & $72 \pm 1.01^{\mathrm{a}-\mathrm{d}}$ & $55 \pm 1.01^{\mathrm{a}-\mathrm{d}}$ \\
\hline Diabetic + RC $\left(200 \mathrm{mg} \mathrm{kg}^{-1}\right)$ & $3.07 \pm 00.04^{\mathrm{a}, \mathrm{c}-\mathrm{e}}$ & $65.5 \pm 2.5^{\mathrm{a}-\mathrm{e}}$ & $46.5 \pm 1.5^{\mathrm{a}-\mathrm{e}}$ \\
\hline
\end{tabular}

${ }^{a}$ Results are expressed as mean \pm S. E. M. and analyzed using one-way ANOVA followed by Bonferroni's test for multiple comparisons. ${ }^{\text {a } P \leq 0.05}$ versus normal group. ${ }^{\mathrm{b}} P \leq 0.05$ versus diabetic group. ${ }^{\mathrm{c}} P \leq 0.05$ versus diabetic + pioglitazone $\left(10 \mathrm{mg} \mathrm{kg}^{-1}\right)$ group. ${ }^{\mathrm{d}} P \leq 0.05 \mathrm{diabetic}+\mathrm{RM}(200 \mathrm{mg}$ $\left.\mathrm{kg}^{-1}\right)$ group, ${ }^{\mathrm{e}} \mathrm{P} \leq 0.05$ diabetic $+\mathrm{RH}\left(200 \mathrm{mg} \mathrm{kg}{ }^{-1}\right)$ group. $n=5$. 


\section{A}
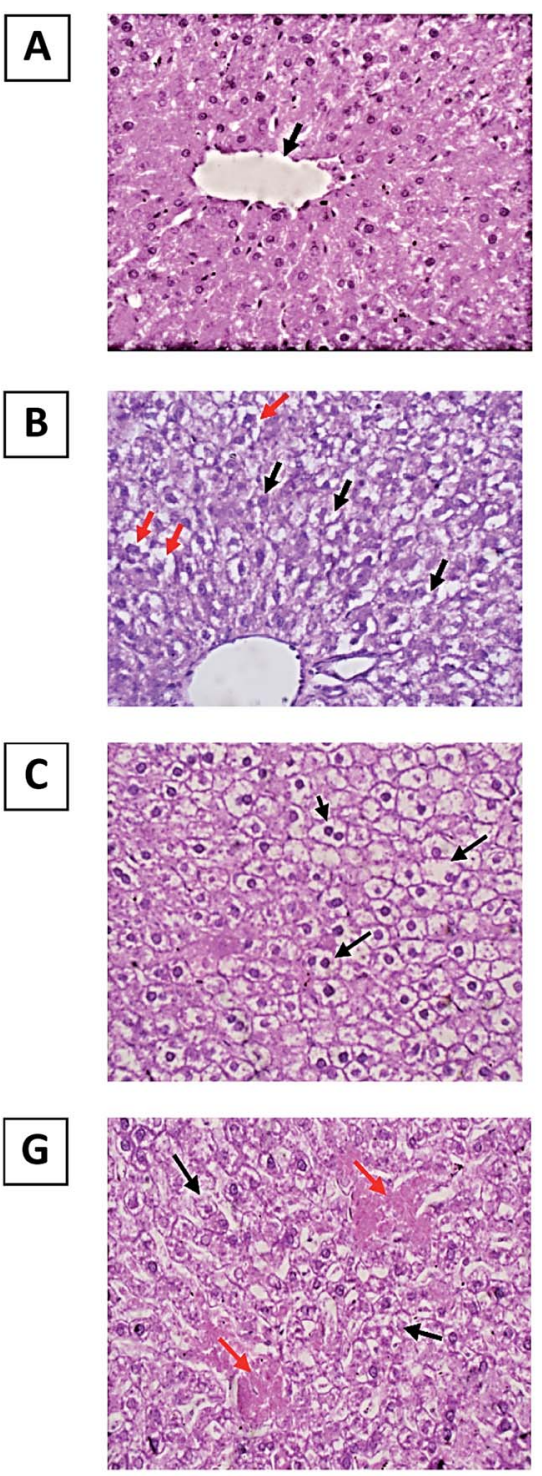

D

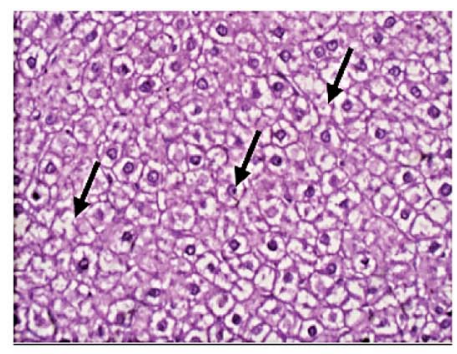

$\mathbf{E}$
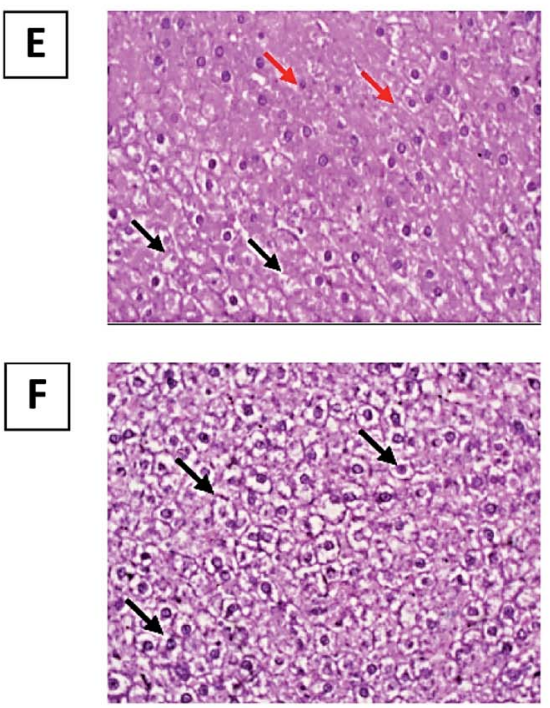

$\mathbf{H}$

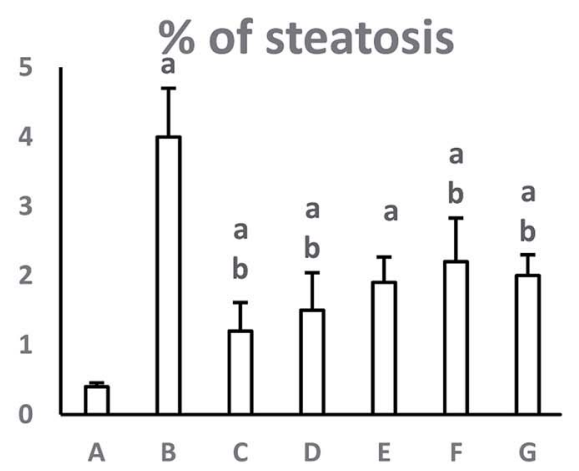

Fig. 1 Histopathological picture for hepatic specimens stained with hematoxylin and eosin with magnification power $40 \times$. (A) Histopathology images for liver sections from normal group uniform hepatocytes arranged in plates radiating from central vein (black arrows) (H\&E, 40X). (B) Diabetic group in which hepatocytes show evidence of injury; hydropic degeneration (black arrows) and steatosis (red arrows) (H\&E, 40×). (C) Diabetic + pioglitazone $\left(10 \mathrm{mg} \mathrm{kg}^{-1}\right)$ shows mild histopathological changes (H\&E, 40x). (D) Diabetic + RM ( $\left.200 \mathrm{mg} \mathrm{kg}^{-1}\right) \mathrm{group}$ which shows mild hitopathological changes. (E) Diabetic + RH (200 mg kg-1) group which shows mild hydropic degeneration of hepatocytes (black arrows) and many hepatocytes show uniform morphology (red arrows) (H\&E, 40×). (F) Diabetic + RC (200 mg kg ${ }^{-1}$ ) which shows moderate degeneration in hepatocytes (black arrows) (H\&E, 40X). (G) Diabetic + RE (200 $\mathrm{mg} \mathrm{kg}^{-1}$ ) which shows moderate hydropic degeneration of hepatocytes (black arrows). Congested sinusoids are seen (red arrows) (H\&E, 40×). (H) Effect of different extracts of Rubia tinctorum and pioglitazone (10 mg kg ${ }^{-1}$ ) on percent of liver steotosis. (A) Normal group. (B) Diabetic group. (C) Diabetic + pioglitazone $\left(10 \mathrm{mg} \mathrm{kg}^{-1}\right)$. (D) Diabetic $+\mathrm{RM}\left(200 \mathrm{mg} \mathrm{kg}{ }^{-1}\right)$. (E) Diabetic + RH (200 mg kg $\left.{ }^{-1}\right)$. (F) Diabetic + RC (200 mg kg $\left.{ }^{-1}\right)$. (G) Diabetic + RE $\left(200 \mathrm{mg} \mathrm{kg}^{-1}\right)$. Results are expressed as mean $\pm \mathrm{S}$. E. M. and analyzed using one-way ANOVA followed by Bonferroni's test for multiple comparisons. ${ }^{\mathrm{a}} P \leq 0.05$ versus normal group. ${ }^{\mathrm{b}} P \leq 0.05$ versus diabetic group. $n=5$.

insulin resistance characteristic of type 2 diabetes mellitus including adiposity, dyslipidaemia, hyperglycaemia and changes in liver and ovaries. ${ }^{32}$ However, its effect in weight gain was previously discussed..$^{33,34}$ On the other hand, its role in decreasing weight gain, enhancing lipid profile and stimulation of lipid mobilization from visceral part to the lower part of body was also reported..$^{35,36}$

The current results are in agreement with these articles, as pioglitazone treatment reduced total body weight and decreased liver-fat resulting in elevation of insulin sensitivity in these tissues. Additionally, the effect of pioglitazone is related to the correct 
Table 4 Effect of different $R$. tinctorum extracts and pioglitazone $\left(10 \mathrm{mg} \mathrm{kg}^{-1}\right.$ ) on lipid profile, serum triglycerides (TG), total cholesterol (TC), high-density lipoprotein (HDL) and low-density lipoprotein (LDL) in the experimental groups of type II diabetes in rats ${ }^{a}$

\begin{tabular}{|c|c|c|c|c|}
\hline Group & Serum TG $\left(\mathrm{mg} \mathrm{dL}^{-1}\right)$ & Serum TC $\left(\mathrm{mg} \mathrm{dL}^{-1}\right)$ & $\mathrm{HDL}\left(\mathrm{mg} \mathrm{dL}{ }^{-1}\right)$ & $\mathrm{LDL}\left(\mathrm{mg} \mathrm{dL}^{-1}\right)$ \\
\hline Normal & $54.5 \pm 3.5$ & $63 \pm 3.03$ & $45 \pm 11$ & $24.5 \pm 0.5$ \\
\hline Diabetic & $161 \pm 16.1^{\mathrm{a}}$ & $116.5 \pm 3.5^{\mathrm{a}}$ & $20 \pm 2.02^{\mathrm{a}}$ & $55.5 \pm 4.5^{\mathrm{a}}$ \\
\hline Diabetic + RM $\left(200 \mathrm{mg} \mathrm{kg}^{-1}\right)$ & $68 \pm 1.01^{\mathrm{b}, \mathrm{c}}$ & $72 \pm 1.01^{\mathrm{a}-\mathrm{c}}$ & $36 \pm 0.5^{\mathrm{b}}$ & $23 \pm 1.01^{\mathrm{b}}$ \\
\hline Diabetic + RH $\left(200 \mathrm{mg} \mathrm{kg}^{-1}\right)$ & $98.5 \pm 0.5^{\mathrm{a}-\mathrm{d}}$ & $89.5 \pm 0.5^{\mathrm{a}, \mathrm{b}, \mathrm{d}}$ & $30.5 \pm 0.5^{\mathrm{a}}$ & $46.5 \pm 0.5^{\mathrm{a}-\mathrm{d}}$ \\
\hline Diabetic + RC $\left(200 \mathrm{mg} \mathrm{kg}^{-1}\right)$ & $85 \pm 2.02^{\mathrm{a}-\mathrm{c}}$ & $82.5 \pm 0.5^{\mathrm{a}-\mathrm{e}}$ & $26 \pm 1.01^{\mathrm{a}, \mathrm{c}}$ & $45.5 \pm 3.5^{\mathrm{a}-\mathrm{d}}$ \\
\hline
\end{tabular}

${ }^{a}$ Results are expressed as mean \pm S. E. M. and analyzed using one-way ANOVA followed by Bonferroni's test for multiple comparisons. ${ }^{a} P \leq 0.05$ versus normal group. ${ }^{\mathrm{b}} P \leq 0.05$ versus diabetic group. ${ }^{\mathrm{c}} P \leq 0.05$ versus diabetic + pioglitazone $\left(10 \mathrm{mg} \mathrm{kg}^{-1}\right)$ group. ${ }^{\mathrm{d}} P \leq 0.05$ diabetic $+\mathrm{RM}(200 \mathrm{mg}$ $\left.\mathrm{kg}^{-1}\right)$ group, ${ }^{\mathrm{e}} \mathrm{P} \leq 0.05$ diabetic $+\mathrm{RH}\left(200 \mathrm{mg} \mathrm{kg}{ }^{-1}\right)$ group. $n=5$.

choice of its dose as lower and higher doses of pioglitazone may exert no or adverse action like sodium water retention and weight gain. ${ }^{37}$ So, the dose of pioglitazone should be monitored and well selected..$^{23}$ In the current study the selected dose was $\left(10 \mathrm{mg} \mathrm{kg}{ }^{-1}\right)$ which is considered to be medium dose and has significant effect in all measured parameters.

Similarly, diabetic rats treated with RM, RC or RE (each $200 \mathrm{mg} \mathrm{kg}{ }^{-1}$ ) extracts showed a significant decrease in final body weight and \% change in body weight, however, only diabetic rats treated with $\mathrm{RM}\left(200 \mathrm{mg} \mathrm{kg}{ }^{-1}\right)$ and $\mathrm{RC}\left(200 \mathrm{mg} \mathrm{kg}^{-1}\right)$ showed a significant improvement in obesity index compared with diabetic group. On the other hand, the group treated with the extract RH (200 mg kg ${ }^{-1}$ ) couldn't show any significant enhancement in final body weight, \% change in body weight or obesity index in comparison with diabetic group at $p \leq 0.05$. Moreover, the results achieved by the treatment with the extract $\mathrm{RM}$ (200 $\mathrm{mg} \mathrm{kg}^{-1}$ ) were the best in improving the decrease \% change in body weight and obesity index (Table 1).

\subsection{Effect of different $R$. tinctorum extracts and pioglitazone (10 $\mathrm{mg} \mathrm{kg}^{-1}$ ) on blood glucose level, serum insulin, insulin resistance and serum leptin level on type II diabetic rats}

The current results showed significant increases in blood glucose level ( $\mathrm{mM} \mathrm{L}^{-1}$ ), serum insulin level $\left(\mathrm{ng} \mathrm{L}^{-1}\right)$, HOMA-IR and serum leptin level $\left(\mathrm{ng} \mathrm{L}^{-1}\right)$ in diabetic group in comparison with normal group at $p \leq 0.05$ (Table 2). However, treatment with pioglitazone $\left(10 \mathrm{mg} \mathrm{kg}^{-1}\right)$ significantly decreased blood glucose level ( $\left.\mathrm{mM} \mathrm{L}^{-1}\right)$, serum insulin level $\left(\mathrm{ng} \mathrm{L}^{-1}\right)$, HOMA-IR and serum leptin level (ng $\left.\mathrm{L}^{-1}\right)$ when compared to diabetic group at $p \leq 0.05$. Additionally, treatment with RM, RH, RC and $\mathrm{RE}$ (each of $200 \mathrm{mg} \mathrm{kg}^{-1}$ ) significantly induced a decrease in blood glucose level $\left(\mathrm{mM} \mathrm{L}^{-1}\right)$, serum insulin level $\left(\mathrm{ng} \mathrm{\textrm {L } ^ { - 1 }}\right)$, HOMA-IR and serum leptin level $\left(\mathrm{ng} \mathrm{L}^{-1}\right)$ when compared to diabetic group at $p \leq 0.05$. However, the most significant results were obtained from the group treated with $\mathrm{RM}\left(200 \mathrm{mg} \mathrm{kg}^{-1}\right)$ concerning normalization of the level of serum leptin $\left(\mathrm{ng} \mathrm{\textrm {L } ^ { - 1 }}\right)$ at $p \leq 0.05$ (Table 2).

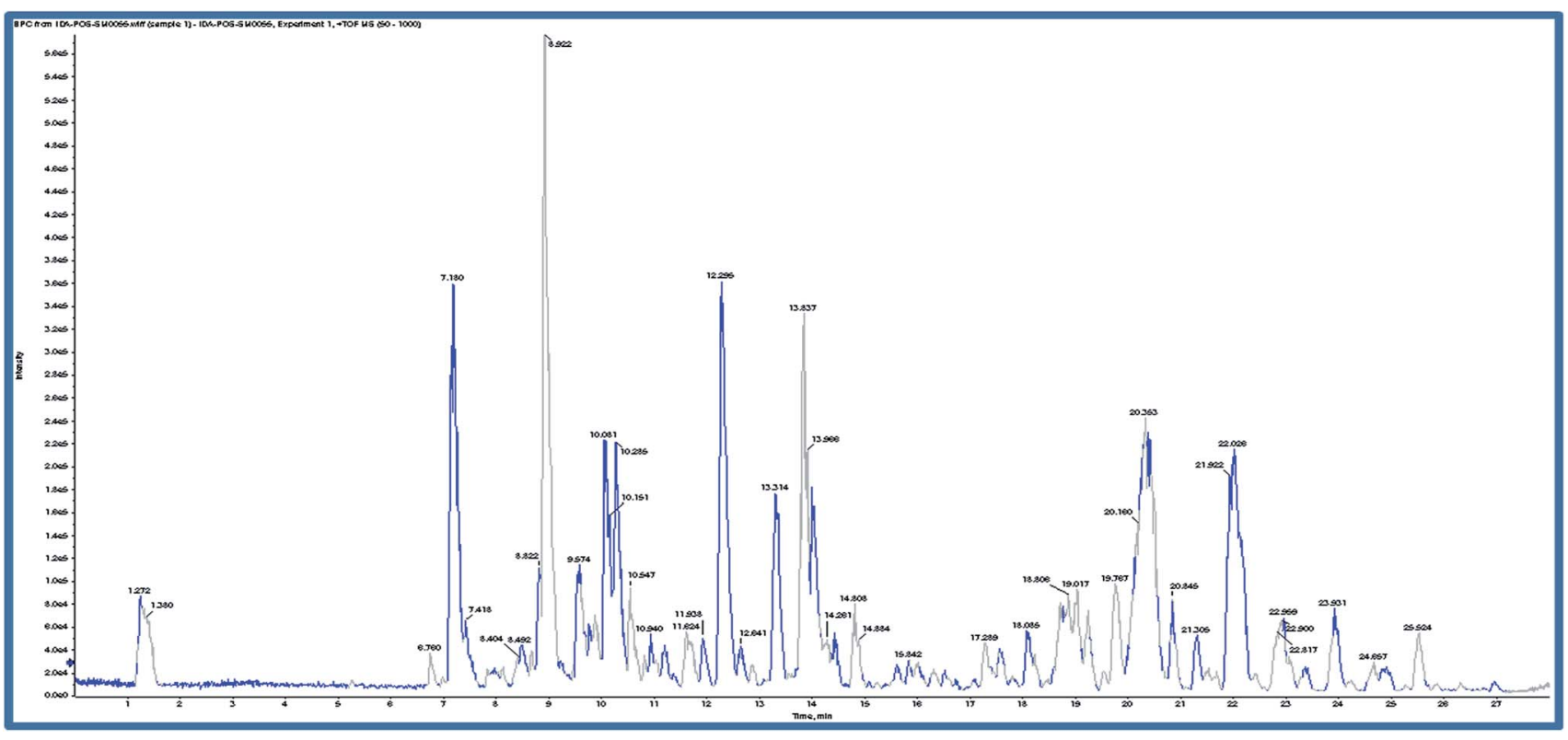

Fig. 2 Chromatogram of methanolic root extract of Rubia tinctorum in positive mode ion. 
Table 5 Anthraquinones previously isolated from Rubia tinctorum root and detected in the extract by LC-HRMS analysis (positive mode) ${ }^{a}$<smiles>[R3]c1ccc2c(c1)C(=O)c1c([R])c([R])c([R])c(c1[R])C2=O</smiles>

\begin{tabular}{|c|c|c|c|c|c|c|c|c|}
\hline \multirow[b]{2}{*}{$R_{t}(\min )$} & \multirow{2}{*}{\multicolumn{2}{|c|}{ Molecular formula $m / z[M+\mathrm{H}]^{+}$}} & \multirow[b]{2}{*}{ Name of the compound } & \multicolumn{5}{|c|}{ Substituents } \\
\hline & & & & $\mathrm{R}_{1}$ & $\mathrm{R}_{2}$ & $\mathrm{R}_{3}$ & $\mathrm{R}_{4}$ & $\mathrm{R}_{5}$ \\
\hline 7.18 & $\mathrm{C}_{26} \mathrm{H}_{28} \mathrm{O}_{14}$ & 565.1557 & Lucidin-3-O-primveroside & $\mathrm{OH}$ & $\mathrm{CH}_{2} \mathrm{OH}$ & $O$-primverose & & $\mathrm{H}$ \\
\hline 8.82 & $\mathrm{C}_{25} \mathrm{H}_{26} \mathrm{O}_{13}$ & 535.1451 & Ruberythric acid & $\mathrm{OH}$ & $O$-Glucose (6-1)xylose & $\mathrm{H}$ & & $\mathrm{H}$ \\
\hline 8.92 & $\mathrm{C}_{15} \mathrm{H}_{8} \mathrm{O}_{7}$ & 301.0348 & Pseudopurpurin & $\mathrm{OH}$ & $\mathrm{COOH}$ & $\mathrm{OH}$ & $\mathrm{OH}$ & I $\mathrm{H}$ \\
\hline 9.57 & $\mathrm{C}_{15} \mathrm{H}_{8} \mathrm{O}_{6}$ & 285.0399 & Munjistin & $\mathrm{OH}$ & $\mathrm{COOH}$ & $\mathrm{OH}$ & & $\mathrm{H}$ \\
\hline $10.08^{*}$ & $\mathrm{C}_{14} \mathrm{H}_{8} \mathrm{O}_{5}$ & 257.045 & Purpurin & $\mathrm{OH}$ & $\mathrm{OH}$ & $\mathrm{H}$ & $\mathrm{OH}$ & I $\mathrm{H}$ \\
\hline $10.28^{*}$ & $\mathrm{C}_{14} \mathrm{H}_{8} \mathrm{O}_{5}$ & 257.045 & Anthragallol & $\mathrm{OH}$ & $\mathrm{OH}$ & $\mathrm{OH}$ & $\mathrm{H}$ & $\mathrm{H}$ \\
\hline $12.29 * *$ & $\mathrm{C}_{14} \mathrm{H}_{8} \mathrm{O}_{4}$ & 241.0501 & Alizarin & $\mathrm{OH}$ & $\mathrm{OH}$ & $\mathrm{H}$ & $\mathrm{H}$ & $\mathrm{H}$ \\
\hline $12.31^{* *}$ & $\mathrm{C}_{14} \mathrm{H}_{8} \mathrm{O}_{4}$ & 241.0501 & Xanthopurpurin & $\mathrm{OH}$ & $\mathrm{H}$ & $\mathrm{OH}$ & $\mathrm{H}$ & $\mathrm{H}$ \\
\hline 12.64 & $\mathrm{C}_{15} \mathrm{H}_{10} \mathrm{O}_{5}$ & 271.0606 & 1,4-Dihydroxy-2-hydroxymethyl anthraquinone & $\mathrm{OH}$ & $\mathrm{CH}_{2} \mathrm{OH}$ & $\mathrm{H}$ & $\mathrm{OH}$ & I $\mathrm{H}$ \\
\hline 12.64 & $\mathrm{C}_{14} \mathrm{H}_{8} \mathrm{O}_{3}$ & 225.0551 & 2-Hydroxy anthraquinone & $\mathrm{H}$ & $\mathrm{OH}$ & $\mathrm{H}$ & $\mathrm{H}$ & $\mathrm{H}$ \\
\hline 13.31 & $\mathrm{C}_{15} \mathrm{H}_{10} \mathrm{O}_{4}$ & 255.0657 & Rubiadin & $\mathrm{OH}$ & $\mathrm{CH}_{3}$ & $\mathrm{OH}$ & $\mathrm{H}$ & $\mathrm{H}$ \\
\hline 13.96 & $\mathrm{C}_{17} \mathrm{H}_{14} \mathrm{O}_{5}$ & 299.0919 & 1,4-Dihydroxy-2-ethoxymethyl anthraquinone & $\mathrm{OH}$ & $\mathrm{CH}_{2} \mathrm{OC}_{2} \mathrm{H}_{5}$ & $\mathrm{H}$ & $\mathrm{OH}$ & I $\mathrm{H}$ \\
\hline $13.77 * * *$ & $\mathrm{C}_{15} \mathrm{H}_{10} \mathrm{O}_{5}$ & 271.0606 & Anthragallol-3-methylether & $\mathrm{OH}$ & $\mathrm{OH}$ & $\mathrm{OCH}_{3}$ & $\mathrm{H}$ & $\mathrm{H}$ \\
\hline $13.83^{* * *}$ & $\mathrm{C}_{15} \mathrm{H}_{10} \mathrm{O}_{5}$ & 271.0606 & Lucidin & $\mathrm{OH}$ & $\mathrm{CH}_{2} \mathrm{OH}$ & $\mathrm{OH}$ & $\mathrm{H}$ & $\mathrm{H}$ \\
\hline $18.08^{* * * *}$ & $\mathrm{C}_{15} \mathrm{H}_{10} \mathrm{O}_{3}$ & 239.0708 & 1-Hydroxy-2-methyl AQ & $\mathrm{OH}$ & $\mathrm{CH}_{3}$ & $\mathrm{H}$ & $\mathrm{H}$ & $\mathrm{H}$ \\
\hline $18.75^{* * * *}$ & $\mathrm{C}_{15} \mathrm{H}_{10} \mathrm{O}_{3}$ & 239.0708 & 7-Hydroxy-2-methyl AQ & $\mathrm{H}$ & $\mathrm{CH}_{3}$ & $\mathrm{H}$ & $\mathrm{H}$ & $\mathrm{OH}$ \\
\hline $18.80^{\#}$ & $\mathrm{C}_{15} \mathrm{H}_{10} \mathrm{O}_{4}$ & 255.0657 & Xanthopurpurin-3-methylether & $\mathrm{OH}$ & $\mathrm{H}$ & $\mathrm{OCH}_{3}$ & $\mathrm{H}$ & $\mathrm{H}$ \\
\hline $19.02^{\#}$ & $\mathrm{C}_{15} \mathrm{H}_{10} \mathrm{O}_{4}$ & 255.0657 & Alizarin-1-methyl ether & $\mathrm{OCH}_{3}$ & $\mathrm{OH}$ & $\mathrm{H}$ & $\mathrm{H}$ & $\mathrm{H}$ \\
\hline $19.53^{\#}$ & $\mathrm{C}_{15} \mathrm{H}_{10} \mathrm{O}_{4}$ & 255.0657 & Alizarin -2-methyl ether & $\mathrm{OH}$ & $\mathrm{OCH}_{3}$ & $\mathrm{H}$ & $\mathrm{H}$ & $\mathrm{H}$ \\
\hline $19.77^{\#}$ & $\mathrm{C}_{15} \mathrm{H}_{10} \mathrm{O}_{4}$ & 255.0657 & Xanthopurpurin-1-methylether & $\mathrm{OCH}_{3}$ & $\mathrm{H}$ & $\mathrm{OH}$ & $\mathrm{H}$ & $\mathrm{H}$ \\
\hline 20.16 & $\mathrm{C}_{15} \mathrm{H}_{10} \mathrm{O}_{4}$ & 255.0657 & 1-Hydroxy-2-hydroxymethyl anthraquinone & $\mathrm{OH}$ & $\mathrm{CH}_{2} \mathrm{OH}$ & $\mathrm{H}$ & $\mathrm{H}$ & $\mathrm{H}$ \\
\hline 20.5 & $\mathrm{C}_{16} \mathrm{H}_{12} \mathrm{O}_{5}$ & 285.0763 & Anthragallol-2,3-dimethylether & $\mathrm{OH}$ & $\mathrm{OCH}_{3}$ & $\mathrm{OCH}_{3}$ & $\mathrm{H}$ & $\mathrm{H}$ \\
\hline 20.84 & $\mathrm{C}_{15} \mathrm{H}_{10} \mathrm{O}_{3}$ & 239.0708 & 2-Methoxy- anthraquinone & $\mathrm{H}$ & $\mathrm{OCH}_{3}$ & $\mathrm{H}$ & $\mathrm{H}$ & $\mathrm{H}$ \\
\hline $21.30^{\# \#}$ & $\mathrm{C}_{16} \mathrm{H}_{12} \mathrm{O}_{4}$ & 269.0814 & Alizarin-dimethyl ether & $\mathrm{OCH}_{3}$ & $\mathrm{OCH}_{3}$ & $\mathrm{H}$ & $\mathrm{H}$ & $\mathrm{H}$ \\
\hline $21.40^{\# \#}$ & $\mathrm{C}_{16} \mathrm{H}_{12} \mathrm{O}_{4}$ & 269.0814 & Xanthopurpurin dimethylether & $\mathrm{OCH}_{3}$ & $\mathrm{H}$ & $\mathrm{OCH}_{3}$ & $\mathrm{H}$ & $\mathrm{H}$ \\
\hline $23.9^{\# \# \#}$ & $\mathrm{C}_{16} \mathrm{H}_{12} \mathrm{O}_{3}$ & 253.0864 & 1-Methoxy methyl anthraquinone & $\mathrm{CH}_{2} \mathrm{OCH}_{3}$ & $\mathrm{H}$ & $\mathrm{H}$ & $\mathrm{H}$ & $\mathrm{H}$ \\
\hline $24.12^{\# \# \#}$ & $\mathrm{C}_{16} \mathrm{H}_{12} \mathrm{O}_{3}$ & 253.0864 & 1-Methoxy-2-methyl anthraquinone & $\mathrm{OCH}_{3}$ & $\mathrm{CH}_{3}$ & $\mathrm{H}$ & $\mathrm{H}$ & $\mathrm{H}$ \\
\hline 25.52 & $\mathrm{C}_{17} \mathrm{H}_{14} \mathrm{O}_{3}$ & 266.0943 & 2-Ethoxymethyl anthraquinone & $\mathrm{H}$ & $\mathrm{CH}_{2} \mathrm{OC}_{2} \mathrm{H}_{5}$ & $\mathrm{H}$ & $\mathrm{H}$ & $\mathrm{H}$ \\
\hline
\end{tabular}

3.3. $\quad$ Effect of different $R$. tinctorum extracts and pioglitazone $\left(10 \mathrm{mg} \mathrm{kg}^{-1}\right)$ on liver index, serum liver enzymes level, hepatic tissue histopathological changes and percent of steatosis on type II diabetic rats

In the current study, diabetic group showed a significant increase in liver index with a value $(3.5 \pm 0.2)$ versus $(2.3 \pm 0.1)$ in normal group at $p \leq 0.05$ (Table 3 ). Diabetic group showed elevation in serum liver enzymes AST and ALT in comparison with normal group at $p \leq 0.05$. Furthermore, treatment of diabetic rats with only pioglitazone $\left(10 \mathrm{mg} \mathrm{kg}^{-1}\right)$ or the extract $\mathrm{RM}$ (200 $\mathrm{mg} \mathrm{kg}^{-1}$ ) for four weeks could significantly normalize the liver index in comparison with diabetic group at $p \leq 0.05$. Additionally, treatment with pioglitazone $\left(10 \mathrm{mg} \mathrm{kg}^{-1}\right), \mathrm{RM}, \mathrm{RH}$, $\mathrm{RC}$ and RE (each $200 \mathrm{mg} \mathrm{kg}^{-1}$ ) significantly induced a decrease in both two serum liver enzymes ALT and AST in comparison with diabetic group at $p \leq 0.05$.

Finally, diabetic group showed evidence of injury; hydropic degeneration (black arrows) and a significant increase in percent of steatosis (red arrows) (H\&E, 40×) when compared to normal group at $p \leq 0.05$ (Fig. 1). Treatment with either pioglitazone $\left(10 \mathrm{mg} \mathrm{kg}^{-1}\right)$ or any of the Rubia extracts showed enhancement in liver architecture and a significant decrease in percent of steatosis with a significant reduction in hydropic degeneration of hepatocytes (black arrows) and many hepatocytes show uniform morphology (red arrows) (H\&E, 40×) in comparison with diabetic group at $p \leq 0.05$ (Fig. 1). However, the results obtained by treatment with the extract RM were the best and closer to the normal group (Table 3 ). 
3.4. Effect of different $R$. tinctorum extracts and pioglitazone (10 $\mathrm{mg} \mathrm{kg}^{-1}$ ) on lipid profile, serum triglycerides (TG), total cholesterol (TC), high-density lipoprotein (HDL) and lowdensity lipoprotein (LDL) on type II diabetic rats

Treatment with high fat diet followed with STZ $\left(30 \mathrm{mg} \mathrm{kg}^{-1}\right)$ in diabetic group resulted in a significant increase in serum triglycerides (TG) (mg dL $\left.{ }^{-1}\right)$, total cholesterol (TC) $\left(\mathrm{mg} \mathrm{dL}^{-1}\right)$ and low-density lipoprotein (LDL) $\left(\mathrm{mg} \mathrm{dL}^{-1}\right)$ and a significant decrease in high-density lipoprotein (HDL) $\left(\mathrm{mg} \mathrm{dL}^{-1}\right)$ in comparison with normal group at $p \leq 0.05$ (Table 4). Treatment with pioglitazone $\left(10 \mathrm{mg} \mathrm{kg}^{-1}\right)$ resulted in a significant decrease in serum triglycerides (TG) ( $\left.\mathrm{mg} \mathrm{dL}^{-1}\right)$, total cholesterol (TC) (mg $\left.\mathrm{dL}^{-1}\right)$ and low-density lipoprotein (LDL) $\left(\mathrm{mg} \mathrm{dL}^{-1}\right)$ and a significant increase in high-density lipoprotein (HDL) (mg $\mathrm{dL}^{-1}$ ) in comparison with diabetic group at $p \leq 0.05$.

Furthermore, all extracts induced a significant decrease in serum triglycerides (TG) $\left(\mathrm{mg} \mathrm{dL}{ }^{-1}\right)$, total cholesterol (TC) (mg
$\left.\mathrm{dL}^{-1}\right)$ and low-density lipoprotein (LDL) $\left(\mathrm{mg} \mathrm{dL}^{-1}\right)$ at $p \leq 0.05$ (Table 4).

Moreover, treatment with $\mathrm{RM}\left(200 \mathrm{mg} \mathrm{kg}^{-1}\right.$ ) resulted in a significant improvement and normalization in high-density lipoprotein (HDL) serum level $\left(\mathrm{mg} \mathrm{dL}^{-1}\right)$ in comparison with diabetic group at $p \leq 0.05$ (Table 4 ).

Accordingly, the results obtained from treatment of the diabetic rats with the methanolic extract of Rubia tinctorum were the best and more close to normal group and pioglitazone treated group either in decreasing body weight, obesity, improving lipid profile, normalization hyperglycaemia, insulin resistance, hyperinsulinemia or in enhancing liver tissue structure and function.

\subsection{LC-HRMS analysis}

Based on the results of the biological activities of different extracts of $R$. tinctorum which revealed that the best extract was the methanolic one, accordingly, the methanolic extract was subjected to

Table 6 Flavonoids of Rubia tinctorum root extract identified by LC-HRMS analysis (positive mode)<smiles>[R6]c1ccc(-c2oc3cc([R4])c([R3])c([R2])c3c(=O)c2[R])cc1[R5]</smiles>

\begin{tabular}{|c|c|c|c|c|c|c|c|c|c|}
\hline$R_{t}(\min )$ & Molecular formula & $m / z[M+H]^{+}$ & Name of the compound & \multicolumn{6}{|l|}{ Substituents } \\
\hline 8.67 & $\mathrm{C}_{27} \mathrm{H}_{30} \mathrm{O}_{15}$ & 593.1507 & Kaempferol-7-neohesperidoside & $\mathrm{H}$ & $\mathrm{OH}$ & $\mathrm{H}$ & $O$-Neohesperidose & $\mathrm{OH}$ & $\mathrm{OH}$ \\
\hline 9.41 & $\mathrm{C}_{28} \mathrm{H}_{32} \mathrm{O}_{15}$ & 607.1663 & Hesperetin-7-O-neohesperidoside & $\mathrm{H}$ & $\mathrm{OH}$ & $\mathrm{H}$ & $O$-Neohesperidose & $\mathrm{OH}$ & $\mathrm{OCH}_{3}$ \\
\hline 10.89 & $\mathrm{C}_{28} \mathrm{H}_{32} \mathrm{O}_{14}$ & 591.1714 & Acacetin 7-rutinoside & $\mathrm{H}$ & $\mathrm{OH}$ & $\mathrm{H}$ & $O$-Rutinose & $\mathrm{H}$ & $\mathrm{OH}$ \\
\hline 11.60 & $\mathrm{C}_{21} \mathrm{H}_{22} \mathrm{O}_{10}$ & 433.1135 & Naringenin-7-O-glucoside & $\mathrm{H}$ & $\mathrm{OH}$ & $\mathrm{H}$ & $O$-Glucose & $\mathrm{H}$ & $\mathrm{OH}$ \\
\hline 12.30 & $\mathrm{C}_{20} \mathrm{H}_{18} \mathrm{O}_{11}$ & 433.0771 & Quercetin-3-D-xyloside & $O$-Xylose & $\mathrm{OH}$ & $\mathrm{H}$ & $\mathrm{OH}$ & $\mathrm{OH}$ & $\mathrm{OH}$ \\
\hline 12.36 & $\mathrm{C}_{21} \mathrm{H}_{20} \mathrm{O}_{11}$ & 447.0928 & Quercitrin & $O$-Glucose & $\mathrm{OH}$ & $\mathrm{H}$ & $\mathrm{OH}$ & $\mathrm{OH}$ & $\mathrm{OH}$ \\
\hline 13.63 & $\mathrm{C}_{21} \mathrm{H}_{20} \mathrm{O}_{10}$ & 431.0978 & Kaempferol-3-O-L-rhamnoside & O-Rhamnose & $\mathrm{OH}$ & $\mathrm{H}$ & $\mathrm{OH}$ & $\mathrm{H}$ & $\mathrm{OH}$ \\
\hline 13.77 & $\mathrm{C}_{22} \mathrm{H}_{22} \mathrm{O}_{12}$ & 477.1033 & Isorhamnetin-3-O-glucoside & $O$-Glucose & $\mathrm{OH}$ & $\mathrm{H}$ & $\mathrm{OH}$ & $\mathrm{OCH}_{3}$ & $\mathrm{OH}$ \\
\hline 13.83 & $\mathrm{C}_{15} \mathrm{H}_{10} \mathrm{O}_{6}$ & 285.0399 & Luteolin & $\mathrm{H}$ & $\mathrm{OH}$ & $\mathrm{H}$ & $\mathrm{OH}$ & $\mathrm{OH}$ & $\mathrm{OH}$ \\
\hline 9.82 & $\mathrm{C}_{28} \mathrm{H}_{36} \mathrm{O}_{15}$ & 611.1976 & Neohesperidin dihydrochalcon & & & & & & \\
\hline
\end{tabular}


LC-HRMS analysis to detect its chemical constituents (Fig. 2). The results showed 45 hits as indicated in Tables 5 and 6.

The anthraquinones were previously reported to be major components of Rubia species specially and family Rubiaceae generally. ${ }^{38}$ Table 5 revealed the presence of 28 anthraquinones. All of the detected compounds were previously reported to be isolated from the Rubia tinctorum. ${ }^{38-41}$

On the other hand, a number of anthraquinones were previously reported to be isolated from the same plant as for example nor damnacanthal and lucidin methyl ether ${ }^{\mathbf{4 2}}$ were not recorded her in the present study. Additionally, family Rubiaceae revealed the presence of a number of flavonoids of which derivatives of quercetin, rhamnetin, isorhamnetin, apigenin and kaempferol are the most common. ${ }^{42}$ In this work a number of 17 flavonoids were recorded as minor constituents of Rubia tinctorum (Table 6). On the other hand, rutin which was previously reported to be isolated from $R$. tinctorum $^{38}$ was not detected here, and instead, quercetrin (which could be considered as a secondary glycoside of rutin) was recorded.

\subsection{Docking study}

$\alpha$-Amylase has been considered as an important therapeutic target for the management of type 2 diabetes mellitus, hence, we aimed to elucidate the binding mode of the tested compounds with $1 \mathrm{HX} 0$ as $\alpha$-amylase inhibitor. ${ }^{43}$ We performed induced fit molecular docking studies with the compounds under investigation. The docking results with docking scores, and the hydrogen bonded residues are given in Table 7. Additionally, 3D representative images of one of the high binding affinities of both anthraquinone and flavonoids compared to AC1 as the co-crystallized ligand are shown in Fig. 3.

As shown in Table 7, most of the tested derivative were docked and bound to amino acids of the receptor binding site with high and mild binding affinities (energies), while other derivatives couldn't be docked. In reference to the cocrystallized ligand (AC1) forms two major interactions with the Val 163 and Gly 106 as the key amino acids residues, we found two of the anthraquinones with high binding affinity $\left(-13.92-21.03 \mathrm{kcal} \mathrm{mol}^{-1}\right)$, and four flavonoids (-16.16-23.56 $\mathrm{kcal} \mathrm{mol}^{-1}$ ) towards $\alpha$-amylase inhibition by forming the same key interactions. Nine of the anthraquinones, and twelve of flavonoids showed mild binding affinities (-9.05-15.45 kcal $\mathrm{mol}^{-1}$ ) and (-16.59-27.45 $\left.\mathrm{kcal} \mathrm{mol}^{-1}\right)$, respectively, as they form only one hydrogen bond with either Val 163 or Gly 106.

As shown in Fig. 3, three-dimensional representation of two highly docked compounds as two active leads relative to the AC1 with moieties of ligand and receptor involved in the interaction, interaction-type, bond-length for each docking procedure. Among anthraquinone, 1-hydroxy-2-hydroxy-methyl anthraquinone forms two hydrogen bonds through the hydroxyl groups as

Table 7 Docking results of the tested compounds with high and mild inside $1 \mathrm{HXO}$ binding site as $\alpha$-amylase inhibitor compared to AC1 as the cocrystallized ligand. Co-crystallized ligand (AC1) inside the binding site of $1 \mathrm{HXO}$ forms $2 \mathrm{HB}$ with the key amino acids Gly 106 and Val $163^{a}$

\begin{tabular}{|c|c|c|c|c|}
\hline Group & Binding affinity & Identified compound & Binding energy $\left(\mathrm{kcal} \mathrm{mol}^{-1}\right)$ & Ligand-receptor interactions with \\
\hline \multirow[t]{11}{*}{ Anthraquinone* } & \multirow[t]{2}{*}{ High } & 1-Hydroxy-2-hydroxymethyl AQ ${ }^{\#}$ & -13.92 & 2 HB with Gly 106 and Val 163 \\
\hline & & Ruberythric acid & -21.03 & 2 HB with Val 163 \\
\hline & \multirow[t]{9}{*}{ Mild } & 1,4-Dihydroxy-2-ethoxymethyl anthraquinone & -9.05 & 1 HB with either Val 163 or Gly 106 \\
\hline & & 2-Hydroxy anthraquinone & -9.36 & \\
\hline & & 2-Methoxy-anthraquinone & -10.43 & \\
\hline & & Lucidin-3-O-primveroside & -24.9 & \\
\hline & & Lucidin & -11.9 & \\
\hline & & Purpurin & -14.78 & \\
\hline & & Xanthopurpurin dimethylether & -11.34 & \\
\hline & & Xanthopurpurin & -11.68 & \\
\hline & & Rubiadin & -15.45 & \\
\hline \multirow[t]{16}{*}{ Flavonoids* } & \multirow[t]{4}{*}{ High } & Baicalein-7-O-glucuronide & -19.66 & 2 HB with Val 163 \\
\hline & & Kaempferol-3-O-L-rhamnoside & -20.95 & 2 HB with Val 163 \\
\hline & & Naringenin-7-O-glucoside ${ }^{\#}$ & -16.16 & 2 HB with Gly 106 and Val 163 \\
\hline & & Neohesperidin dihydrochalcon & -23.56 & 2 HB with Gly 106 \\
\hline & \multirow[t]{12}{*}{ Mild } & Acacetin 7-rutinoside & -21.21 & 1 HB with either Val 163 or Gly 106 \\
\hline & & Apigenin & -16.59 & \\
\hline & & Hesperetin & -20.98 & \\
\hline & & Hesperetin-7-O-neohesperidoside & -25.20 & \\
\hline & & Isorhamnetin-3-O-glucoside & -22.21 & \\
\hline & & Kaempferol-7-neohesperidoside & -17.04 & \\
\hline & & Luteolin & -18.08 & \\
\hline & & Luteolin-3-7-diglucoside & -18.38 & \\
\hline & & Luteolin-7-O-glucoside & -27.45 & \\
\hline & & Naringenin & -17.67 & \\
\hline & & Quercetin-3-D-xyloside & -19.95 & \\
\hline & & Quercetin & -20.89 & \\
\hline
\end{tabular}

${ }^{a}{ }^{\#}$ Highly-bonded interactive docked compounds in the same way like AC1. *The rest of compounds of both groups weren't able to bind with the receptor pocket. 


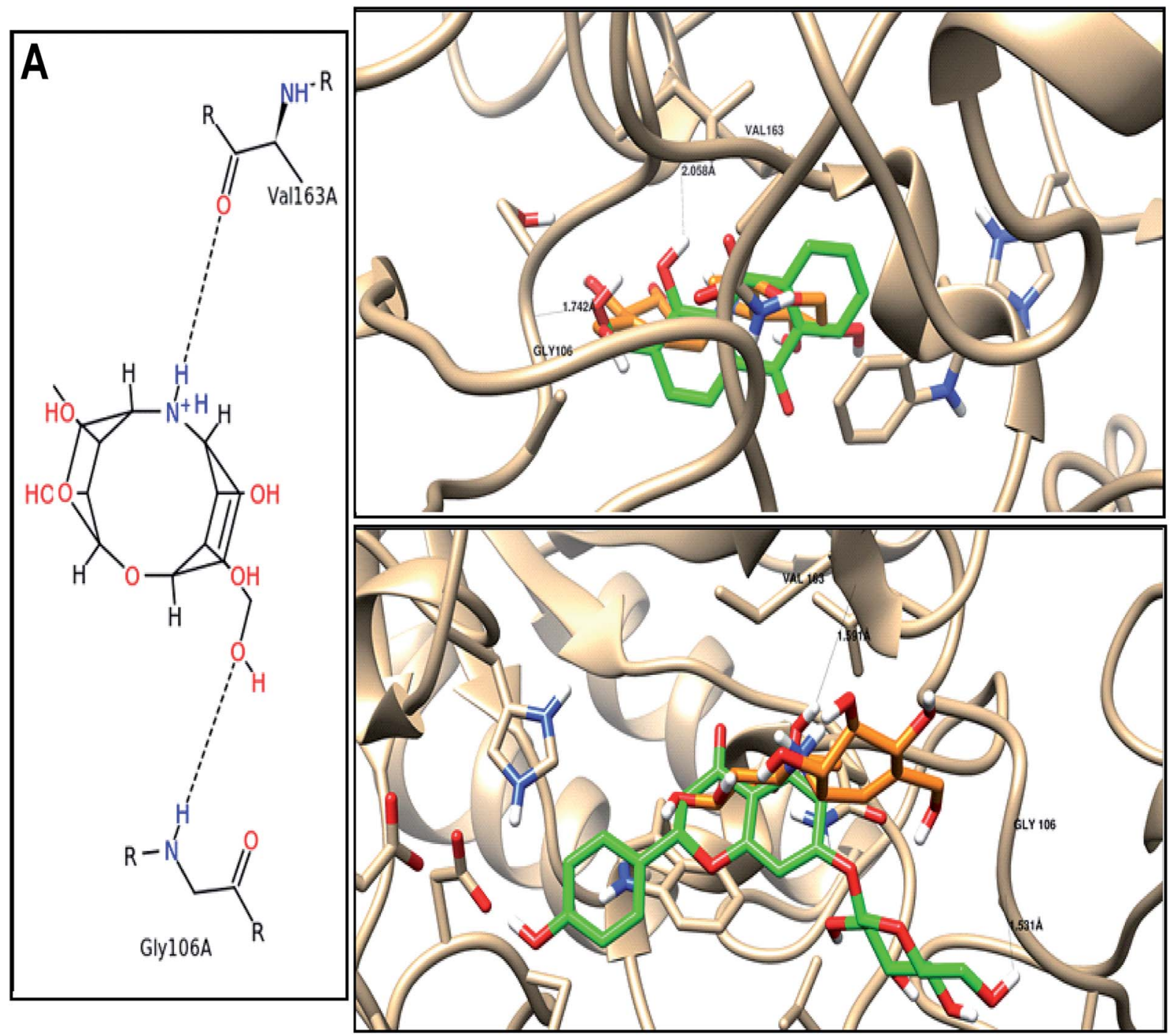

Fig. 3 Binding disposition and ligand-receptor interactions of (A) co-crystallized ligand (AC1), and the two high affinity. Docked compounds; (B) 1-hydroxy-2-hydroxymethyl $A Q$, and (C) naringenin-7-O-glucoside inside the $1 \mathrm{HXO}$ binding site as alpha-amylase inhibitor. Co-crystallized ligand (orange), and docked compounds (green).

H-donor with Val 163 with bonds length $2.05 \mathrm{~A}$, and H-acceptor with Gly 106 with bonds length 1.74 A. Among flavonoids, naringenin-7-O-glucoside forms two hydrogen bonds through the hydroxyl groups as H-donors with Val 163 and Gly 106 with bonds length 1.59 and $1.53 \AA$.

From docking study, we conclude the good affinity of compounds under investigation through their hydroxyl and carbonyl active groups that bind inside the tested target ( $\alpha$-amylase inhibition compared to AC1), which is correlated to anti-diabetic activity.

In addition to $\alpha$-amylase inhibition activity, most of the compounds detected in the extract proved to possess antioxidant and anti-inflammatory activities. ${ }^{4-46}$ It is well known that both activities play an important role in treatment of diabetes mellitus. ${ }^{47,48}$ This also can justify the activity of the methanolic extract of Rubia tinctorum which accumulate a great number of compounds showing antioxidant, anti-inflammatory and $\alpha$-amylase inhibition activities.

\section{Conclusions}

The current study proved that the methanolic extract of Rubia tinctorum showed significant results in decreasing body weight, improving lipid profile, normalizing hyperglycaemia, insulin resistance, hyperinsulinemia in addition to enhancing liver tissue structure and function. There activities could be attributed to its chemical constituents that exert antioxidant, antiinflammatory and $\alpha$-amylase inhibition activities. As indicated by the docking study, 1-hydroxy-2-hydroxymethyl anthraquinone and naringenin-7-O-glucoside were the most potent as $\alpha$ amylase inhibitors.

\section{Conflicts of interest}

There are no conflicts to declare. 


\section{Acknowledgements}

This publication was supported by the Deanship of Scientific Research at Prince Sattam Bin Abdulaziz University, Alkharj, Saudi Arabia as well as Suez Canal University, Ismailia, Egypt.

\section{References}

1 J. R. Petrie, T. J. Guzik and R. M. Touyz, Can. J. Cardiol., 2018, 34(5), 575-584.

2 S. S. Khalaf, M. M. Hafez, E. T. Mehanna, N. M. Mesbah and D. M. Abo-Elmatty, Int. J. Res. Pharm. Biomed. Sci., 2019, 3, 114.

3 B. Saad, H. Zaid, S. Shanak and S. Kadan, in Anti-diabetes and Anti- obesity Medicinal Plants and Phytochemicals, Springer Nature, Switzerland, 2017, vol. 1, pp. 3-19.

4 Y. Shi and F. B. Hu, Lancet, 2014, 383, 1947-1948.

5 W. J. Sandborn and W. A. Faubion, Curr. Gastroenterol. Rep., 2000, 2, 440-445.

6 K. N. Abdel-Khalik, M. M. El-Ghani and A. R. Elkordy, Turk. J. Bot., 2008, 32, 353-359.

7 N. H. Tan and J. Zhou, Chem. Rev., 2006, 106, 840-895.

8 S. M. Zhao, B. Kuang, J. T. Fan, H. Yan, W. Y. Xu and N. H. Tan, Chimia, 2011, 65, 952-956.

9 K. Xu, P. L. Wang, B. Yuan, Y. T. Cheng, Q. Li and H. M. Lei, Chem. Cent. J., 2013, 7, 81-110.

10 K. Xu, P. L. Wang, L. Wang, C. M. Liu, S. X. Xu, Y. T. Cheng, Y. H. Wang, Q. Li and H. M. Lei, Chem. Biodiversity, 2014, 11, 341-363.

11 H. E. Ahmed, I. F. Tahoun, I. Elkholy, A. B. Shehata and Y. Ziddan, Dyes Pigm., 2017, 145, 486-492.

12 J. Bellakhdar, R. Claisse, J. Fleurentin and C. Younos, J. Ethnopharmacol., 1991, 35, 123-143.

13 H. Jouad, M. Haloui, H. Rhiouani, J. El Hilaly and M. Eddouks, J. Ethnopharmacol., 2001, 77, 175-182.

14 M. Eddouks, M. Maghrani, A. Lemhadri, L. M. Ouahidi and H. Jouad, J. Ethnopharmacol., 2002, 82, 97-103.

15 M. El Haouari and J. A. Rosado, Phytother. Res., 2016, 30, 1059-1071.

16 M. Adams, C. Berset, M. Kessler and M. Hamburger, J. Ethnopharmacol., 2009, 121, 343-359.

17 R. T. Gunther, J. Goodyer, The Greek herbal of Dioscorides. New York: Hafner Publishing, 1959.

18 K. Agarwal and R. Varma, J. Ethnopharmacol., 2015, 174, 1724.

19 F. Z. Marhoume, M. A. Laaradia, Z. Younes, J. Laadraoui, S. Oufkir, R. Aboufatima, A. Chait and A. Bagri, J. Ethnopharmacol., 2019, 241, 111971.

20 L. Rashan, H. Lukmanul, F. Heinz, K. Gerhardt, M. Irmgard, A. Mohammed and H. Sidgi, Jordan J. Biol. Sci., 2018, 11, 489-494.

21 F. Z. Marhoume, Z. Younes, H. Boufous, N. Errafiy, M. Ait Laaradia, J. Laadraoui, A. Hakmaoui, B. Abdellah and C. Abderrahman, Eur. J. Med. Plants, 2017, 20, 1-10.

22 H. Nejat, K. Sedaghat, A. Vakili, M. Jarrahi and M. Z. Khorasani, Jundishapur J. Nat. Pharm. Prod., 2017, 12(3), e64319, DOI: 10.5812/jjnpp.64319.
23 D. M. Khodeer, S. A. Zaitone, N. E. Farag and Y. M. Moustafa, Can. J. Physiol. Pharmacol., 2016, 94, 463-476.

24 Z. A. Saad, D. M. Khodeer, S. A. Zaitone, A. A. M. Ahmed and Y. M. Moustafa, Life Sci., 2020, 253, 117725, DOI: 10.1016/ j.lfs.2020.117725.

25 S. Zaitone, N. Hassan, N. El-Orabi and E.-S. El-Awady, Eur. J. Pharmacol., 2011, 662, 70-77.

26 M. Pan, Y. L. Song, J. M. Xu and H. Z. Gan, J. Pineal Res., 2006, 41, 79-84.

27 C. C. Allain, L. S. Poon, C. S. Chan, W. Richmond and P. C. Fu, Clin. Chem., 1974, 20, 470-475.

28 P. Fossati and L. Prencipe, Clin. Chem., 1982, 28, 2077-2080.

29 D. R. Matthews, J. P. Hosker, A. S. Rudenski, B. A. Naylor,

D. F. Treacher and R. C. Turner, Diabetologia, 1985, 28, 412-419.

30 M. Qian, V. Nahoum, J. Bonicel, H. Bischoff, B. Henrissat and F. Payan, Biochemistry, 2001, 40, 7700-7709.

31 M. S. Nafie, M. A. Tantawy and G. A. Elmgeed, Steroids, 2019, 152, 108485.

32 S. Banerjee, J. Assoc. Physicians India, 2012, 60, 62-66.

33 J. Rosenstock, S. W. Kim, M. A. Baron, R.-P. Camisasca, F. Cressier, A. Couturier and S. Dejager, Diabetes, Obes. Metab., 2007, 9, 175-185.

34 D. Russell-Jones, R. M. Cuddihy, M. Hanefeld, A. Kumar, J. G. González, M. Chan, A. M. Wolka and M. K. Boardman, Diabetes Care, 2012, 35, 252-258.

35 N. Kodama, N. Tahara, A. Tahara, A. Honda, Y. Nitta, M. Mizoguchi, H. Kaida, M. Ishibashi, T. Abe, H. Ikeda, J. Narula, Y. Fukumoto, S. Yamagishi and T. Imaizumi, J. Clin. Endocrinol. Metab., 2013, 98, 4438-4445.

36 P. K. Shah, S. Mudaliar, A. R. Chang, V. Aroda, M. Andre, P. Burke and R. R. Henry, Diabetes, Obes. Metab., 2011, 13, 505-510.

37 D. K. McGuire and S. E. Inzucchi, Circulation, 2008, 117, 440449.

38 G. C. H. Derksen and T. A. van.Beek, Stud. Nat. Prod. Chem., 2002, 26, 629-684.

39 G. Cuoco, C. Mathe, P. Archier, F. Chemat and C. Vieillescazes, Ultrason. Sonochem., 2009, 16, 75-82.

40 L. Ford, C. M. Rayners and R. S. Blackburn, Phytochemistry, 2015, 117, 168-173.

41 I. Essaidi, A. Snoussi, H. Ben Haj Koubaier, H. Casabianca and N. Bouzouita, Pigm. Resin Technol., 2017, 46, 379-384.

42 D. Martins and C. V. Nunez, Molecules, 2015, 20, 1342213495.

43 C. Proença, M. Freitas, D. Ribeiro, S. M. Tomé, E. F. T. Oliveira, M. F. Viegas, A. N. Araújo, M. J. Ramos, A. M. S. Silva, P. A. Fernandes and E. Fernandes, J. Enzyme Inhib. Med. Chem., 2019, 34, 577-588.

44 P. Rathee, H. Chaudhary, S. Rathee, D. Rathee, V. Kumar and K. Kohli, Inflammation Allergy: Drug Targets, 2009, 8, 229-235.

45 P. G. Pietta, J. Nat. Prod., 2000, 63, 1035-1042.

46 Y. Gow-Chin, D. Pin -Der and C. Da-Yon, Food Chem., 2000, 70, 437-441.

47 J. L. Evans, I. D. Goldfine, B. A. Maddux and G. M. Grodsky, Diabetes, 2003, 52, 1-8.

48 S. Gothai, P. Ganesan, S.-Y. Park, S. Fakurazi, D.-K. Choi and P. Arulselvan, Nutrients, 2016, 8, 461. 